\title{
Difficulties in Reading English Words: How do Japanese Learners Perform on a Test of Phonological Deficit?
}

\author{
David Coulson, Mayumi Ariiso, Rina Kojima and Masami Tanaka \\ University of Niigata Prefecture \\ doi: http://dx.doi.org/10.7820/vli.v02.1.coulson.et.al
}

\begin{abstract}
The motivation for this research is the observation of frequent read-aloud miscues among Japanese university students, and the slow rate of reading on simplified graded readers by many post-secondary learners. We investigate what components of the second-language reading complex may remain undeveloped. Word recognition in different languages employs different phonological processes; so inadequately developed skill in the foreign language processes may lead to poor decoding. This situation requires formal assessment. However, practical tests of wordrecognition skill for second-language learners are not well developed. Therefore, we adapted a test from Wydell and Kondo, replicating their methodology to test the phonological skill of a Japanese-English bilingual diagnosed with dyslexia. We do not assume dyslexia among Japanese English learners. Rather, the use of this test format aims to elucidate the state of phonological skill of word-recognition ability in ordinary learners. The subjects were university students at discrete proficiency levels. The results show that this skill can be remarkably underdeveloped. The average skill of subjects with lower proficiency was similar to the objective standard of Wydell and Kondo's English-reading disabled subject. Higher-proficiency subjects performed much better. The results do not imply dyslexia, although some lower-proficiency students may, in fact, be English-dyslexic. Instead, they focus attention on the lack of appropriate reading skills development in English education in Japan, and its possible effect on overall proficiency. This situation principally indicates a need for prolonged phonics training and more extensive L2 reading.
\end{abstract}

\section{Introduction}

Extensive reading (ER) is essential for L2 acquisition (e.g. Hunt \& Beglar, 2005). However, it is not easy to develop the component skills to read freely, and enjoyably, in a foreign language, especially when the L1 and L2 writing systems are typologically different. Unfortunately, the Japanese curriculum devotes insufficient time to ER, or even decoding skills. Reading in any L2 can be tiring when the writing systems are similar, before considering the effort necessary when they are not. Due to the "Matthew Effect" (Stanovich, 1985), whereby people read more if they find it comfortable and less if they do not, a gap opens between more- and lessable learners. Those left behind may never catch up. Ongoing practice to develop 
automatic decoding is essential. This is because early gains in reading fluency development are not robust. Indeed, many Japanese students' reading skill of basic words actually regresses upon entering high school after early, rapid progress towards word-decoding fluency in junior high school (Coulson, Forthcoming in 2014). The lexically dense texts used in high schools do not promote fluent. Overall, due to a lack of cumulative consolidation, even the skill of reading the highestfrequency vocabulary, learned in junior high school, rapidly erodes. This is likely to be one of the causes of many reading miscues. Reading speed is also found wanting in many Japanese EFL learners. Grabe (2009) recommends that ESL learners aim for 300 words per minute. Even on graded readers, most Japanese students read significantly more slowly, at about 180 words per minute. This tardiness indicates considerable effort, and hence rapid fatigue and possible loss of motivation.

Vocabulary instruction, and assessment, must take account of the decoding challenges faced by Japanese students. Nation's description (2001, p. 27) of what it means to know a word creates three basic categories of Form, Meaning and Use. Nation further subdivided each of these categories into active and passive components. One example is knowing what a word looks like (passive) and how it is spelled (active). Although tests for Nation's other categories, such as size and association, have become well known (e.g. the Vocabulary Levels Test; Nation, 1990), research on practical L2 word-recognition assessment has yet to make a similar impact (e.g. Coulson, 2010).

Concerning the points above, this paper asks what assessing English L2 learners with tests of reading sub-skills, commonly applied for testing dyslexia, will reveal.

\subsection{Characteristics of dyslexia in L1 and L2}

Dyslexia symptoms usually include delayed and poor reading, with persistent confusion over the direction of similarly shaped letters (e.g. "b" and "d") (e.g. Wolf, 2008). This leads to mistaken identification of words in reading and transposition of letters in writing (e.g. "pot" for "top"). According to the British Dyslexia Association, about $10 \%$ of the population of the United Kingdom is dyslexic, and 4\% severely so in some form. Dyslexia is associated with loss of selfesteem, and possibly a loss of motivation in education. If difficulties appear in reading English as a foreign language, caused by similar phonological deficits as those seen in true dyslexia, it could well have an impact on motivation and interest in English.

Concerning such problems, it is possible for people to be apparently normal readers of their first language, but to display dyslexic symptoms in another language. (e.g. Meara, Coltheart, \& Masterson, 1985). This is especially the case where the L1 uses a transparent writing system with a consistent correspondence between sound and spelling, such as Spanish, and where the L2 uses a much more opaque writing system, such as English. Japanese is a complicated case, but the syllabic "kana" system does employ a highly regular correspondence between sounds and symbols. No estimate exists for how many Japanese L2 English learners may be English-dyslexic, but it is plausible the figure is similar to that in English- 
speaking countries. According to Meara et al. (1985) "it seems reasonable to guess the incidence of severe reading problems of ... [dyslexia]... will be about the same as it is for native English speakers." (p. 34).

However, the concern in this paper is principally with undeveloped, rather than disabled, reading. Nevertheless, the two problems can both be assessed using a test of phonological processing to check for deficits.

\subsection{The importance of phonology in reading}

A study on profoundly deaf children (Hanson, Liberman, \& Shankweiler, 1984) found that few were skilled readers. The common point of these children was, obviously, their inability to hear. However, reading deaf children were shown to have phonological awareness of words. Consequently, reading involves not only orthographic and semantic activation stemming from visual input, but also the ability to "establish and make use of linguistically recoded representations of the language" (p. 378).

\subsection{Dyslexia testing for L2 English learners}

We suggest that the skills required for fluent decoding by L2 English learners may be assessed by dyslexia tests. For Japanese learners, L1 reading occurs at the syllable level and is highly consistent. In English, reading requires the mapping of graphemes onto sub-syllable units in which there is much contextual variation. Whichever system we learn first has a persistent effect on reading in new writing systems, resulting in a sub-optimal sound conversion.

Further, comparison to the single subject in Wydell and Kondo's study is warranted as this represents an established, objective standard.

\subsection{The replicated paper}

Wydell and Kondo (2003) investigated AS, a bilingual English-Japanese who previously confirmed (Wydell \& Butterworth, 1999) as severely dyslexic in English. He was raised in Japan and his Japanese reading skill was unaffected. AS studied in Britain for a degree. After this period, the researchers tested his ability. He, and other normal-reading subjects (English native speakers and Japanese graduate students in Britain), read aloud target stimuli and decided whether these were real or non-words. Second, they were shown items which do not exist in English but resemble the sound of actual words (e.g. "neym" for "name"). Since they do not exist in memory, such "pseudohomophones" require the ability to apply English grapheme-phoneme rules to letter strings to create a phonological match to the real English word. Poor performance, a classic symptom of dyslexia, results in a faulty phonological code, and this can prevent the subject from realizing the item is identical in pronunciation to a real English word. Finally, they also used a "spoonerising" task where the task is to transpose the initials of two words and pronounce them (e.g. "tilk mea" for "milk tea"). This task requires the manipulation of phonemes, so this task effectively reflects the state of English 
reading development. A summary of Wydell and Kondo, whose methodology this paper replicates, is shown in the Results section (Table 1).

\section{Method}

\subsection{Subjects}

Thirty-three Japanese first-year university students participated in this study. They had all taken a placement test (TOEFL ITP; score range: 310-677) and been assigned to three levels for English classes. Two of the levels were selected for this investigation: fourteen participants in the "advanced" class and nineteen in the "basic" class. The mean TOEFL score gap between the groups was 80 points. The stimulus words were chosen from English textbooks for Japanese junior high school students (New Horizon 2, years 1, 2, and 3, 2008). Participants were assumed to have studied these words and to know them as translation equivalents.

\subsection{Test instrument}

The test battery consisted of three parts. Test 1 had 120 high-frequency words mixed with 40 pronounceable non-words (e.g. yake, quisp). Forty items were printed on each page. Subjects read these words aloud and judged whether they were real words. If the subject thought the word was real, he/she marked it with a circle. The test had 40 words per page over 4 pages. Test 2 had 150 pseudohomophones (resembling real words when read aloud; e.g. sitty, eniwan, muvee) mixed with pronounceable nonwords. Subjects were asked to read these words aloud. If they thought a word is a pseudohomophone, they marked it with a circle. Test 3 was a spoonerising test where the initial phonemes of a compound word had to be exchanged. The researchers pronounced each compound word and subjects answered. There were 10 items.

Student researchers sat with each participant in a quiet room. They instructed them to proceed quickly and accurately. The number of correctly pronounced items and errors was recorded. Each interview required about 20 minutes.

\section{Results}

Table 1 shows data from AS, the single subject in Wydell and Kondo (2003), and Table 2 shows the corresponding data for the 33 subjects in our replicated investigation.

AS (148 points) scored less than other Japanese subjects whose score (156) was almost identical to native speakers (158). In Test 2, the pseudohomophone task was difficult for the Japanese participants and especially so for AS. He fell far behind the other Japanese students, with 30 errors in 50 items. Japanese students in turn were far behind native speakers, for whom the test posed almost no difficulty.

Moving onto Table 2, the two groups of university subjects in this investigation performed statistically similarly to each other in Test 1 . However, the mean score of the Basic Class (7.8 points) was closer to AS than to the Advanced 
Table 1. A Summary of the Results Reported by Wydell and Kondo (2003) ( $\mathrm{n} .=13)$

\begin{tabular}{|c|c|c|c|c|c|c|}
\hline & $\begin{array}{l}\text { Non-words } \\
\text { (40) \# of } \\
\text { mistakes }\end{array}$ & $\begin{array}{c}\text { Test } 1 \\
\text { (160 items) } \\
\text { Real-words } \\
\text { (120) \# of } \\
\text { mistakes }\end{array}$ & $\begin{array}{l}\text { Total } \\
\text { score }\end{array}$ & $\begin{array}{c}\text { Pseudo- } \\
\text { words (50) } \\
\# \text { of } \\
\text { mistakes }\end{array}$ & $\begin{array}{c}\text { Test } 2 \\
\text { (200 items) } \\
\text { Non-words } \\
\text { (150) \# of } \\
\text { mistakes }\end{array}$ & $\begin{array}{l}\text { Total } \\
\text { score }\end{array}$ \\
\hline AS & 7 & 5 & 148 & 30 & 11 & 159 \\
\hline $\begin{array}{l}\text { Native Japanese } \\
\mathrm{n} .=6\end{array}$ & 3 & 1 & 156 & 16 & 5 & 178 \\
\hline $\begin{array}{l}\text { Native English } \\
\mathrm{n} .=6\end{array}$ & 2 & 0 & 158 & 1 & 1 & 198 \\
\hline
\end{tabular}

Table 2. The Results from the Present Investigation ( $\mathrm{n} .=33$ )

\begin{tabular}{|c|c|c|c|c|c|c|}
\hline & $\begin{array}{l}\text { Non-words } \\
(40) \# \text { of } \\
\text { mistakes }\end{array}$ & $\begin{array}{c}\text { Test } 1 \\
\text { (160 items) } \\
\text { Real-words } \\
\text { (120) \# of } \\
\text { mistakes }\end{array}$ & $\begin{array}{l}\text { Total } \\
\text { score }\end{array}$ & $\begin{array}{c}\text { Pseudo- } \\
\text { words (50) \# } \\
\text { of mistakes }\end{array}$ & $\begin{array}{c}\text { Test } 2 \\
\text { (200 items) } \\
\text { Non-words } \\
\text { (150) \# of } \\
\text { mistakes }\end{array}$ & $\begin{array}{l}\text { Total } \\
\text { score }\end{array}$ \\
\hline $\begin{array}{c}\text { Basic class } \\
\text { n. }=19\end{array}$ & $\begin{array}{r}7.8 \\
\text { SD } 3.3\end{array}$ & $\begin{array}{cc} & 2.6 \\
\text { SD } 1.9\end{array}$ & $\begin{array}{c}149.5 \\
\text { SD } 4.0\end{array}$ & $\begin{array}{ll} & 19.7 \\
\text { SD } 11.1\end{array}$ & $\begin{array}{r}8.1 \\
\text { SD } 2.2\end{array}$ & $\begin{array}{c}161.8 \\
\text { SD } 24.4\end{array}$ \\
\hline $\begin{array}{l}\text { Advanced } \\
\text { Class } \\
\text { n. }=14\end{array}$ & $\begin{aligned} & 5.3 \\
& \text { SD } 2.4\end{aligned}$ & $\begin{array}{c}0.8 \\
\text { SD } 0.9\end{array}$ & $\begin{array}{l}153.9 \\
\text { SD } 2.2\end{array}$ & SD 2.2 & $\begin{array}{r}9.9 \\
\text { SD } 2.2\end{array}$ & $\begin{array}{r}180.8 \\
\text { SD } 5.2\end{array}$ \\
\hline
\end{tabular}

Class. In Test 2, the mean number of mistakes of the Basic Class (19.7 mistakes in 50 items) was significantly more than the Advanced class $(p<0.01, t=2.4)$. Regarding the score of the Basic Class in Test 2, a noticeable aspect is the very large degree of variation in their performance $(\mathrm{SD}=11.1)$ on pseudohomophones in comparison to the Advanced Class. They performed in a much narrower range $(\mathrm{SD}=2.2)$. Notably, four students from the Basic Class had a lower score than AS.

The spoonerising test results are largely consistent with the results above. Table 3 shows that the Basic Class mean is more similar to AS than to the Advanced Class. English native speakers have an advantage over all groups.

Table 3. Spoonerising Task: All Results

\begin{tabular}{lc}
\hline & $\begin{array}{c}\text { Test } \mathbf{3} \text { (10 items) } \\
\text { Score }\end{array}$ \\
\hline (Wydell \& Kondo) & \\
AS & 5 \\
English Native Speakers & 9.3 \\
(This study) & \\
Basic Class & 4.7 \\
Advanced Class & 7.8 \\
\hline
\end{tabular}




\section{Discussion}

In this paper, we aimed to assess the phonological sub-skills of the lowestproficiency students in contrast to the highest. There was a very significant difference in phonological-processing skills. The Basic Class performance was lower on each test, but in particular there was a distinct difference between the results of Test 1 and Test 2. In Test 2, the pseudohomophones require well-developed phonological ability. In Test 1 , the use of Real Words did not cause nearly as much trouble for the Basic Class members. It can be concluded that the very highfrequency words selected for this task were recognized as sight vocabulary by both groups, albeit with a slight advantage for the Advanced Class (Ehri, 2005). WadeWoolley (1999) demonstrated that Japanese learners of English are able to strategically bypass the use of phonological processing in reading English words and still rapidly recognize words. However, based on our findings, it would not be true to claim that Japanese can do without processing skill without incurring some cost in word-reading efficiency. As shown, weaker phonological ability coincides with lower proficiency in English. Specifically, there is a clear gap between the more-proficient and the less-proficient class on the tasks which need automatic phonological processing. Overall, this skill is difficult for Japanese people to develop in English reading, and even Japanese graduate students capable of doing research through the medium of English exhibit a persistent deficit in such processing. It is probable that such individuals, and students of the Advanced Class, have some aptitude in developing coping strategies. As for the Basic Class students, on average they perform on our replicated test as if they were dyslexic to some degree.

It does not follow that any subject reported here is dyslexic. However, the Basic Class showed a remarkably high level of variation on the pseudohomophone task. This was mainly due to the poor performance of five individuals (confirmed as outliers by the Smirnov-Grubbs method). Importantly, the scores of four of these five students were worse than AS on the corresponding pseudohomophone task in Wydell and Kondo's study. Removing their data brings the mean score of the Basic Class into a similar range as the Advanced Class (11.9 points, SD 5.2 versus 11.1 points, SD 2.2). Therefore, a much smaller deficit than that shown in Table 2 separates most of the students in our investigation.

Nevertheless, this still leaves a disparity in phonological processing between students who are more and less capable in English. Measures, such as earlier and long-lasting phonics training, are clearly required. Specifically, a systematic focus on decoding should considerably increase. We believe elementary school is the appropriate stage to start this. Especially, in-service training would be ideal to raise teachers' awareness of the difficulties of learning to read English. An early start would help prevent many Japanese students falling into a persistent low-level of English decoding as shown in our data.

The lack of ability of students, especially, in the Basic Class, probably stems also from a lack of ER practice. In fact, the results of Test 2 suggest all students in this study would benefit from much more reading practice. ER is essential for developing speed in reading, and it can be considered that this is based on rapid decoding efficiency, making use of both phonological and orthographic processes. 
A discussion of educational responses to improving word-reading fluency in secondary schools is available in Coulson (forthcoming in 2014).

Finally, concerning the outliers in the Basic Class, the gap in performance from their peers is so wide that the notion that they may be dyslexic can be considered. Their number in the group 5/33 (15\%) exceeds only slightly the proportion the British Dyslexia Association considers as being affected. However, a formal evaluation would be necessary to assess this.

\section{Conclusion}

Greater awareness of the difficulties in learning to read in English is needed by primary and secondary-school teachers, especially regarding the special challenges of learning to read in a new writing system. Intervention for struggling students is also essential. Chronic lack of ER practice, typical in Japanese secondary education, likely explains a large part of underdeveloped phonological processing skills seen in all students. This should be addressed by allowing students ample time to master the basics of English reading (i.e. through systematic phonics training), recognizing the fundamental differences between the Japanese and English orthographies.

If the five students identified as having a level of phonological processing equivalent to the dyslexic individual in Wydell and Kondo's study were to some degree dyslexic, they would have likely found learning English dispiriting without the adequate English L2 input from reading required to steadily acquire the language. However, we make no claims for their actual status since we are not qualified to make such a diagnosis. Generally, students with very limited print exposure are likely have delayed reading competence, in addition to poor decoding skills.

In future research, we will interview testees prior to a similar testing round to understand more about their schooling, and personal learning histories which may have influenced the development of their reading skill. This may reveal pertinent details skill that are not reflected by our purely quantitative approach.

\section{Acknowledgement}

My thanks go to Howard Brown for making class time available for this research.

\section{References}

British Dyslexia Association. Retrieved from http://www.bdadyslexia.org.uk/

Coulson, D. (2010). Q_Lex: A Quick Test of Visual Recognition for Learners of English. Unpublished PhD Dissertation. University of Wales.

Coulson, D. (Forthcoming in 2014). The development of word reading skill in secondary schools in East Asia. In R. Al Marooqi \& R. Roscoe (Eds.), Focusing on EFL Reading: Theory and Practice. Newcastle upon Tyne: Cambridge Scholars Publishing. 
Ehri, L.C. (2005). Development of sight word reading: phases and findings. In M.J. Snowling \& C. Hulme (Eds.), The Science of Reading (pp. 135-152). Oxford: Blackwell Publishing.

Grabe, W. (2009). Reading in a second language. Moving from theory to practice. Cambridge: Cambridge University Press.

Hanson, V.L., Liberman, I.Y., \& Shankweiler, D. (1984). Linguistic coding by deaf children in relation to beginning reading success. Journal of Experimental Child Psychology, 37, 378-393. doi:10.1016/0022-0965(84)90010-9

Hunt, A., \& Beglar, D. (2005). A framework for developing EFL reading vocabulary. Reading in a Foreign Language 1. Retrieved from http://nflrc. hawaii.edu/rfl/april2005/hunt/hunt.html

Meara, P., Coltheart, M., \& Masterson, J. (1985). Hidden Reading Problems in ESL Learners. TESL Canada Journal, 3 (1), 29-36.

Nation, I.S.P. (1990). Teaching and Learning Vocabulary. New York, NY: Newbury House Publishers.

Nation, I.S.P. (2001). Learning Vocabulary in Another Language. Cambridge: Cambridge University Press. doi:10.1017/CBO9781139524759

New Horizon 2 (1, 2 \& 3). (2008). Tokyo Shoseki Kabushiki Kaisha.

Stanovich, K.E. (1985). Matthew effects in reading: Some consequences of individual differences in the acquisition of fluency. Reading Research Quarterly, 21 (4), 360-407. Retrieved from http://www.psychologytoday.com/ files/u81/Stanovich_1986_.pdf

Wade-Woolley, L. (1999). First language influences on second language word reading: All roads lead to Rome. Language Learning, 49 (3), 447-471. doi:10.1111/0023-8333.00096

Wolf, M. (2008). Proust and the Squid. Thriplow, Cambridge: Icon Books.

Wydell, T.N., \& Butterworth, B.L. (1999). A case study of an English-Japanese bilingual with monolingual dyslexia. Cognition, 70, 273-305. doi:10.1016/ S0010-0277(99)00016-5

Wydell, T.N. \& Kondo, T. (2003). Phonological deficit and the reliance on orthographic approximation for reading: a follow-up study on an EnglishJapanese bilingual with monolingual dyslexia. Journal of Research in Reading, 26, 33-48. doi:10.1111/1467-9817.261004 